\title{
Reasonable Adjustments in Learning Programs: Teaching Length, Mass and Capacity to Students with Intellectual Disability
}

\author{
Jelene Du Plessis ${ }^{1}$, Bronwyn Ewing ${ }^{2, *}$ \\ ${ }^{1}$ Beenleigh Special School, Australia \\ ${ }^{2}$ School of Teacher Education and Leadership, Faculty of Education, Queensland University of Technology, Australia
}

Copyright $\subseteq 2017$ by authors, all rights reserved. Authors agree that this article remains permanently open access under the terms of the Creative Commons Attribution License 4.0 International License

\begin{abstract}
Developed in concert with twelve special schools (Prep to Year 12) in Queensland, this paper regarding reasonable adjustments that promote quality differentiated teaching practice in special education math classrooms represents the knowledge and expertise of fifty teachers in special education. Survey responses and empirical evidence suggest that three conclusions are warranted: 1) That a focus on reasonable adjustments which is highly individualised, comprehensive and ongoing, needs to be strengthened to positively affect student learning and progression; 2) Neither assessment of student learning in mathematics or failure to respond to the results is sufficient for making judgements about students' learning; and 3) special education teachers do require strong knowledge and skill with differentiating their teaching practice to ensure that students access the curriculum at appropriate year levels.
\end{abstract}

Keywords Mathematics Education, Special Education, Reasonable Adjustments

\section{Introduction}

Eleven years ago the Australian government made law The Disability Discrimination Act (DDA) Education Standards (Commonwealth of Australia, 2005) [1] which instituted the first steps towards a quality education for all people with disability. The Standards were formulated under the Disability Discrimination Act 1992 (DDA) and provide a framework to ensure that students with disability are able to access and participate in education on the same basis as other students. The Standards also provide clarity for education and training providers to provide reasonable adjustments in learning programs for students with disability. The motivation for this shift in policy was the "increasing understandings of the nature of disability and of the place of people with disabilities in the wider community" (Dickson, 2013, p. 25) [2].

Disability, described as the social restrictions that people with impairments experience, is now regarded as a large extent, a social construction (cf. Liachowitz, 1988, Dickson, 2013) [3, 2]. This construction stems from society's failure to accommodate the different needs of people with impairments and is now a rights issue rather than a welfare issue. "People with disability claim the same basic rights as people without impairments, including a right to educational opportunities" (Dickson, 2013, p. 25) [2].

In Australia a distinction is made between students with disability as defined under the DDA and the Education Standards in mainstream schools as well as special schools and specialist support classes and include:

- $\quad$ students who have formally diagnosed disability by an allied health practitioner

- students who may not have a formal disability diagnosis but have impairment that requires an adjustment or can be supported through quality differentiated teaching

- $\quad$ students with intellectual, physical, sensory and social/emotional disability as well as students with difficulties in learning or behaviour due to disability and,

- students who are gifted and talented and who are impacted by disability (Education Services Australia, 2014)[4].

The new legislation mandates that all Australian schools and education providers evaluate the nature and impact of a student's disability and its effect on their capacity to participate. Schools and education providers are obliged to make reasonable adjustments to ensure that students with disability have access to the curriculum and participate in education the same as their peers.

Although the main impetus behind this policy was to set out the rights of students with disability in education 
(Commonwealth of Australia, 2005)[1], it was also in line with more recent developments from international organisations such as the Organisation for Economic Cooperation and Development (2011)[5], UNESCO (2009)[6], EADSNE (2012)[7] and, UNICEF (2014)[8] and countries such as Finland (Jahnukainen, 2011)[9], Italy (Ferri, 2015)[10], Canada (Alberta Education, 2016)[11] and the United States (US Department of Education, 2008)[12]. According to a number of international conventions, including the UN Rights of the Child Article 24 (UNICEF, 2007)[13] and the UNESCO Salamanca Statement (1994)[14] placing children in special education schools began to be viewed as an infringement on the right to equal opportunity (Bakker, Denessen, Bosman, Krijger \& Bouts, 2007)[15].

This right was inspired by research informed by the contact hypothesis (Allport, 1954, Maras \& Brown, 2000)[16,17]. This hypothesis suggests that children who experience difficulties in learning, will benefit cognitively and socio-emotionally if they are learning with their peers in mainstream schools. Contact, per se between abled and disabled children was thought to have positive effects on their attitudes toward one another and their learning. However, questions have been raised in a number of studies about the benefits of inclusive education on children's socio-emotional well-being.

A landmark study by Bryan (1974)[18] and more recent studies have shown that children overrepresented in rejected or ignored groups were children with learning disabilities and were underrepresented in popular groups (Kuhne \& Wiener, 2000, Stone \& La Greca, 1990, Bakker \& Bosman, 2003)[19,20,21]. Whilst the results from the studies contradict the contact hypothesis, it remains unclear what causes the underrepresentation in the popular group. Two assumptions have been investigated and tested: "the students' level of academic achievement, and status as "a child with LD" contributing to a lower level of acceptance" (Bakker, et al., 2007, p. 48) [15]. The evidence from Bakker and Bosman's (2003) [21] study supported the former while Wiener, Harris and Shirer's (1990) [22] evidence supported the latter. Bakker and Bosman (2003) [21] found that socio-emotional well-being of children with LD was more positive in special education schools than in general education settings. This result suggests that children with LD may be better off in special education schools. However, caution is needed with interpreting these results as the study did not examine whether the socio-emotional well-being of children was related to academic achievement.

Referral for enrolment in a special education school in Queensland is the responsibility of the Chief Executive of Department of Education and Training in Queensland, the Principal and professional committee of individual schools, who make decisions informed by the child's documented evidence (Department of Education and Training, 2016)[23]. Before a child can be enrolled at a special school:

- The student must be diagnosed with a disability, or have a suspected disability that requires significant educational support. The diagnosis must include intellectual impairment.

- $\quad$ The disability must be verified, or be likely to be verified, as meeting the Education Queensland criteria for intellectual impairment.

- $\quad$ The special school must agree that the adjustments made at the school can meet the educational needs of the students (Department of Education and Training, 2016) [23].

Schools generally assess the functional impact of the student's disability in relation to education when considering reasonable adjustments. This includes the impact on communication, mobility, curriculum access, personal care and social participation. Other areas that might be considered for some students are safety, motor development, emotional wellbeing, sensory needs and transitions. This criteria mimics the evidence from Bakker, et al., (2007)[15] study of Dutch schools and the situation in UK schools.

In concluding this discussion, students' learning disabilities can be complex and challenging for teachers in special education and who may not necessarily have the additional training required. Further, teachers in mainstream education are less likely to have completed specialised training (Bakker, et al., 2007)[15]. From a study that investigated mathematics teaching and learning in twelve special schools in Australia Ewing (2016b)[24] found that only $35 \%$ of participating teachers $(\mathrm{N}=48)$ identified as having a qualification in the special education field, for example, autism studies. Although teachers were found to have experience in lieu of specific educational qualifications. Labour market research data on school teachers in Australia reports that $48 \%$ of teachers of special needs children in primary school had less than one year of tertiary study in this area (Department of Employment, 2015, p. 16-17)[25]. Given that the entire population of special education schools has learning disabilities highlights that the load for teachers is far more complicated and complex than in mainstream schools.

This raises the question of whether this holds for all special education teachers or for teachers in mainstream education who teach children with learning disabilities. Whatever the case, teachers in special education are required to make reasonable adjustments in a child's learning program so that they can access the curriculum. Reasonable adjustments reflect the assessed individual needs of the student and what can be adjusted when planning, teaching and learning, curriculum and resources. Adjustments may involve a range of combinations, for example, a) modifying programs and adapting curriculum delivery and assessment strategies, b) providing ongoing consultancy support or professional learning and training for staff, c) specialised technology or computer software or equipment and, d) additional personnel such as therapists or aides for personal care or mobility assistance. 


\section{Purpose of This Study}

In Australia, very little research has been conducted on making reasonable adjustments to the mathematics curriculum for children with intellectual disabilities. Results of such a study may well be different from the results of similar studies in the United States and the UK which dominate the international literature on this topic. One reason may be that the curriculum is organised differently in the UK (Clough, 2006)[26] and the United States (Mulcahy et al., 2016)[27]. Another reason is that a number of studies about mathematics and special education have been performed with students with learning difficulties and emotional and behavioural disorders - most of the studies focused on the full range of developmental disabilities rather than focusing on students with significant intellectual disabilities (Browder et al., 2008)[28]. Moreover, the multiple strands and topics of mathematics is limited to number in the studies, therefore it is not clear what evidence exists for teaching the knowledge and skills for length in the measurement strand (Australian Curriculum Reporting and Assessment Authority, 2011a)[29].

As special schools search to find practical ways to make reasonable adjustments in mathematics learning programs for their students, it becomes increasingly important for researchers and teachers to document how this can be achieved through specific interventions that are research informed to address the challenges and complexities that teachers experience.

\section{Methodology}

An action research/appreciative inquiry (AI) approach was used in the study to examine how teachers taught mathematics to the students (Ford \& Ashford, 2000, Hammond, 1996) [30,31]. AI has been identified as a reconfiguration of action research within organisational settings such as schools. It is described as a strategic planning model, participatory, and a system-wide approach that seeks to discover what works based on solutions that exist currently within organisations such as schools.

\subsection{The Intervention}

The YuMi Maths for Special Schools is an intervention program designed for special education teachers of students from Prep to Year 12 in Queensland (Ewing, 2016b)[24]. It combines a range of instructional procedures drawn from Indigenous approaches to learning: reality, abstraction, mathematics and reflection (RAMR) (Matthews, 2008) [32], Payne and Rathmell's (1975)[33] theory of mathematics learning, and Bruner's (1960)[34] three modes of representation (enactive, iconic and symbolic).

Briefly, RAMR involves:

- $\quad$ R: Learning through awareness of local cultural and environmental knowledge and experiences about the idea; constructing and participating in kinaesthetic activities that introduce the idea and are relevant in terms of knowledge and experience.

- A: Learning through the process of abstracting the idea from reality and representing it using the body-hands-mind; creating representations of it using the hands-body-mind-multisensory experiences, materials, language, and symbols.

- $\quad$ M: Learning through enabling the appropriation of formal language and symbols for mathematical ideas; practising to become familiar with all aspects of the idea.

- R: Learning through connecting the idea back to reality, enabling the validation and justification of one's own knowledge; using reflective strategies flexibility, generalising, reversing, and changing parameters.

Each phase builds on, and is connected to, the previous phase to stimulate and encourage conceptual understanding. The program involved four one-day workshops (4 days across 2 years) for principals and four three-day workshops (12 days across 2 years) for teachers. The workshops focused on school change and leadership, culture, philosophy and pedagogy, and the Australian Mathematics Curriculum strands of Number (including Early Maths Processes and Operations), Measurement, Geometry, Algebra, and Statistics and Probability (ACARA, 2011a)[29].

This study was conducted during the 2015 school year in Everleigh Woods Special School (not its real name). This school provides specialised education programs for students with an intellectual disability from Prep to Year 12. The majority of the students also have another disability. The school is located in a wide, fairly low socio-economic catchment area in Queensland. The term socio-economic is defined as socioeconomic disadvantage in terms of people's access to material and social resources as well as their ability to participate in society (Australian Bureau of Statistics, 2006)[35].

Teachers were selected by the school leadership team to participate in the study based on their approaches to teaching mathematics, interest and aspirations to professional learning about mathematics. Four teachers participated. This paper draws on one portfolio from one of the four participating teachers, who is also a co-author of this article. Although students were not involved in the project at a primary level, teachers were asked to analyse and report their progress as they trialled a range of pedagogical strategies that involved making reasonable adjustments to the students' mathematics learning programs. The student cohort in the Early Years 1 class varied between 5 and 6 years of age. They all had an intellectual disability and either Autism (ASD), Visual Impairment (VI), Hearing Impairment (HI) or Physical Impairment (PI). Four out of the six students were non-verbal. They accessed the Australian Curriculum at the General Capabilities Level $1 \mathrm{~b}$ and $1 \mathrm{c}$ for Literacy and Level 1a for Numeracy (Australian Curriculum Reporting and 
Assessment Authority, 2011b)[36]. They were not able to engage in standardised tasks or tests due to the complex nature of their disabilities. Each child had an Individual Curriculum Plan that stated the extent of individual adjustments required to facilitate their learning and to help them reach their full potential. They were divided into two groups based on the broad outcomes of assessing their abilities.

The Early Years 1 class at Everleigh Woods State School, has a full-time teacher and a full-time teacher aide. The majority of the students are verified, or awaiting verification of their intellectual disabilities. They often present with additional challenges and/or conditions.

\subsection{Data Collection Strategy}

The adoption of reflective portfolios as a research strategy in the project aimed to engage teachers in their own learning as well as that of students. Through this process, teachers could trial new pedagogical strategies as well as create new professional learning collaborations with their colleagues. However, the teachers needed to believe that they could perform instructionally related tasks that were likely to bring about reasonable adjustments and increased student learning.

Ethics approval to conduct this study was granted by the authors' University Human Research Ethics Committee (Approval number 1300000001) and the Department of Education, Training and Employment, Queensland. Participant consent was sought in written form using university ethics approved participant information and consent forms.

\section{Early Years 1: Jelene's Reflection}

Genuine acknowledgement and respect of the complex and challenging contexts that special education teachers teach in is a necessary step towards the successful implementation of an intervention program. The analysis and reflection provides a discussion of the mathematics (measurement) planned and taught by the teacher. In doing so, it brings to light the challenges with assessing the students individually and then from that evidence, making reasonable adjustments in planning and instruction to ensure students are progressing in their learning. In what follows the teacher, Jelene, provides a reflection that focuses on three keys elements: 1) planning and the application of the RAMR model, 2) reasonable adjustments and differentiating the curriculum for individual students and, 3) the measurement topics of length, mass and capacity.

\subsection{About Jelene}

Jelene is a Senior Teacher with 29 years teaching experience in both the independent and public education sectors in Australia and South Africa. During her time as a Master of Special Education student at Griffith University,
Queensland and subsequently in her role as special needs teacher at a number of special schools she has developed an aptitude to efficiently adapt and modify the general education curriculum to enable students with special needs to experience reasonable success. Jelene integrates assistive technology and multimedia into the classroom setting and promotes learning experiences that allow students to manipulate resources in her role as mentor teacher to undergraduate Bachelor of Education students. Involvement in this project has provided many opportunities for Jelene to reflect on her practice, make changes when and where necessary and develop a much richer understanding of the significance of making reasonable adjustments in her teaching to ensure all students are engaged and learning about measurement concepts.

\subsection{Planning process}

As part of the planning and teaching process I was required to use the Australian Foundation to Year 10 Mathematics Curriculum content descriptions, the General Capabilities and the Early Years Curriculum (ACARA, 2011b, 2011a, QCAA, 2006)[29, 36, 37]. These documents worked to support me with knowing the content focus on lessons and making the necessary adjustments to support students with their learning. In my classroom the descriptions for the Early Years 1 learning program included:

- Content Strand: Measurement content descriptor: Use direct and indirect comparisons to decide which is longer, heavier or holds more, and explain reasoning in everyday language.

- General Capabilities: Level 1a - Use Measurement estimates and measure with metric units.

- Early Years Curriculum: Early Numeracy - Children build early mathematical understandings about number by investigating and communicating about quantities and their representations, and attributes of objects and collections.

Coupled with mindful and intentional planning, I broadly categorised the students into two groups based on an interview-based assessment of their capabilities and understandings. The goals in the students' Individual Curriculum Plans were also considered during the planning process.

\subsection{Reality for the Teacher and Students: Where Are They Now?}

To identify where the students were in their learning of the measurement attributes, I designed activities to match their capabilities as existing standardised tests were not sufficient to assess students who experience multiple challenges. The Guidance Officer attempted to administer the Wechsler Preschool and Primary Scale of Intelligence Third Edition (WPPSI-III) (Wechsler, 2012) [38] to determine their 
academic aptitude but had to terminate the tests as a result of lack of concentration, distractibility and difficulty in following instructions. I identified two core groups of students:

- Group 1: Asha, Celia, Joe, Rosco were all non-verbal and working at Literacy level $1 \mathrm{~B}$. This implicates that they could access numeracy activities through Literacy. Asha and Celia did the pre- and post-test. Joe did not do the pre-test but was present for the post-test. Rosco did the pre-test but did not attempt the post-test due to extended days absent.

- Group 2: Fraser, Rose were verbal and could engage in reciprocal conversation to demonstrate their understanding.

The four non-verbal students in Group 1 were introduced to concrete objects used to assess their understanding of big/small, long/short, heavy/light, empty/full. I named the objects and encouraged the students to manipulate them. I used and modelled appropriate language related to the measurement attributes and allowed the students to represent their understanding in a range of ways using their hands, bodies, materials and own language and gesture.

Although the students in Group 1 engaged in manipulating the objects, they did not demonstrate a significant understanding of the measurement attributes presented. To explain, Asha accurately chose two out of the eight objects and identified long and short objects, however, her responses did not demonstrate a clear understanding of the attributes as she simply grabbed and tapped the objects on the desk without making eye contact. This was a typical response from Asha whenever she got hold of a tangible object. Celia attempted eight questions but all attempts were incorrect. She did not engage with me at all and manipulated and threw the objects. Joe did not sit the pre-test as previously mentioned. Rosco responded accurately to three out of the eight questions in the pre-test and demonstrated some understanding of measurement attributes that could be developed further through targeted multi-sensory tasks.

The two verbal students in Group 2 engaged in more structured activities to give me the opportunity to observe their knowledge and understanding of measurement attributes. Both students performed very differently and needed very different strategies to support their ability to demonstrate their understanding. Fraser was presented with an assessment task that contained printed stimuli. He was quite distracted and needed much prompting to stay on task. Although some interesting observations were made, this assessment task did not give me a clear indication of Fraser's existing knowledge of the measurement attributes. Fraser performed much better when physical stimulus materials were presented so he could manipulate them. He managed to stay on task and made quick and accurate responses. Of interest was that both students did not attempt question 1 of the pre-test, identifying long objects. Rose gave seven out of eight correct responses, although she had to be kept on task. Rose became distracted when the printed task was attempted therefore it was terminated. She did however, demonstrate a basic understanding of measurement attributes that could be further developed to improve her understanding of them further. The identification of where the students were at, enabled me to plan and make reasonable adjustments to all the students' learning programs for the next eight weeks.

\subsection{Where Will the Teacher Take the Students Next?}

Over the next eight weeks the students were immersed in experiences and language that was aimed at strengthening and increasing their awareness of the measurement attributes and non-standard units. Even before any assessment was conducted it became clear that the attribute of length, capacity and mass was very unfamiliar to the children. This could be explained by their lack of motor skills that typical people use automatically to complete tasks, for example, to pour water into a container without bumping it over, to talk and enquire about something, to compare lollies in order to eat the biggest one. Hyperactivity and fatigue further jeopardised the students' ability to engage in tasks in a meaningful way.

\subsection{Abstracting from Reality and Creating Representations: How Will the Teacher Teach the Students the Measurement Attributes?}

Taking the students' and my realities into consideration, I planned functional play-based activities using the Abstraction phase of the RAMR cycle to enhance the students' ability to use measurement attributes in meaningful and deliberate ways. I actively observed the students as they engaged in purposeful activities to develop their understanding of the measurement attributes whilst at the same time continually making adjustments to the activities to accommodate students' growing understandings and learning needs. To do this, I drew on the five stages of teaching measurement, commencing with Stage 1 (see for example, Wilson \& Rowland, 1993)[39]. In this stage, the students needed to know and understand what the attributes of measurement were. That understanding was usually learned most efficiently by making a variety of comparisons. The comparison examples should include other attributes that might possibly be confused with length. Such examples allowed the children to realise that each of other attributes were not length.

Stage 1 involved identifying the attributes of the measures length, capacity and mass. Students were engaged in a sequence of representational kinaesthetic activities to develop their understanding of the attributes of these measures. Some examples of activities during weeks one to three included using the language of the attributes to describe an object, for example, long, short, tall, line, heavy, light, empty, full. I presented the items to the students and engaged them in discussions to develop the language associated with the attributes. BIGmack switches with appropriate symbols were used to encourage non-verbal students to express their 
understanding. A BIGmack is a communication device that has a large activation surface which is used to simplify selection processes for students. It is designed for students with motor, visual or cognitive impairments (Spectronics, 2015)[40].

As the students worked through the activities, they were guided by my instructions to explore and find things in the room that were short, long, tall, heavy, light, full or empty. They were given a picture symbol/word card to match with the object. Role play situations were created where the students had to select appropriate toys/equipment to demonstrate measurement attributes, for example, collect teapot and cups to make a cup of tea, get long foam shapes to build a road for the truck, what objects will make the see-saw go up/down, how will I get water in the bottle and how much water is needed?

Near the conclusion of this teaching and learning sequence of activities I administered a post-test that was based on the pre-test to determine the students' developing understandings. The following questions were considered as part of the post-test:

- Was the Student Familiar with the Attribute?

- Has the student acquired the ability to perceive similarities and differences in attributes?

- Does the student know the specific language that is used for describing particular comparisons of attributes?

In Group 1 Rosco did not sit the post-test. Asha and Celia attempted the questions and Joe attempted one and got it correct. When comparing the pre- and post-test results for Asha and Celia there appears to be minimal movement in the outcomes. In Group 2 Rose did not sit the test and Fraser attempted all questions and got them correct. A graph is not necessary to demonstrate this result.

Based on the outcomes I identified that comparison activities in Stage 2 of the measurement framework could not be undertaken until the attributes and the associated language had been established. Joe and Asha were not yet demonstrating a developing understanding of the specific language used to describe the measures regardless of being provided with ample modelling and practice. Both students enjoyed the tactile input they got from holding certain objects. Celia and Rosco were beginning to manipulate objects by trying to put items in containers. Although they attended to the BIGmack switches they were not yet intentionally using it to express their thinking, therefore it cannot be said that they had a sufficient understanding of the language of the measures. Rose consistently demonstrated an understanding of short, long and tall, and she could identify things that were heavy and light. She could tell when a container was full or empty but she confused 'more' and 'less'. Fraser consistently demonstrated sufficient understanding of the language of the length, capacity and mass. He accurately answered basic questions that related to the measures but he did not apply his knowledge in different situations.

\subsection{Abstracting from Reality and Creating Representations: Where Will I Take the Students next?}

Stage 2 involved comparing and ordering the measures. Comparing is a process of determining whether two objects or events are the same or different in relation to specific attributes. It is the forerunner of ordering and measuring. To be able to compare the students must be: 1) be familiar with the attribute, 2) have acquired the ability to perceive similarities and differences and, 3) know the specific language that is used for describing comparisons. Number is not used generally in this stage.

Students engaged in abstraction activities to determine whether two objects were the same or different in relation to specified attributes (comparing). Once students identified the attribute in focus for a measurement task it was possible to compare objects according to the attribute and to order objects according to increasing or decreasing amounts of the attribute.

Joe and Asha continued to be exposed to items that had vastly different attributes to enhance their awareness of short, long, heavy, light, empty and full. Celia and Rosco's ability to use Alternative and Augmentative Communication (AAC) systems to express their understanding of concepts was further developed. AAC systems "includes all forms of communication (other than oral speech) that are used to express thoughts, needs, wants, and ideas" (Sevcik \& Romski, 2016)[41]. The students were encouraged to manipulate materials and be exposed to efficient use of resources for specific purposes through modelling and exploratory opportunities. I demonstrated comparing to enhance their ability to perceive similarities and differences. Rose and Fraser engaged in activities to compare and order objects by considering the attributes that relate to measurement.

\subsection{How Will I Teach Content so the Students Learn?}

The examples of stage 2 activities included comparing and ordering the measurement attributes. Literacy texts such as Whose Nose?, Dear Zoo, In My Pocket, We're Going on a Bear Hunt were used for students at Literacy Level $1 \mathrm{~b}$ to enhance awareness and language related to the measurement attributes. Group 1 students manipulated objects by trying to fit them into containers. I modelled language that related to measurement attributes such as tall, big, long. Group 2 students were encouraged to compare two animals and order three animals according to an attribute, asking questions such as, which animal has the longest nose?

Integrated learning activities were design encompassing social and personal learning, and the natural world. Asha and Joe stirred a bowl full of cream (Social and Personal Learning). Rosco blew the short party blow-out to make it long during oro-motor activities, that is, activities that use the muscles of the mouth and or mouth movements. I modelled the use of language while the Rosco performed the action. 
Rose filled the watering can to water the small tree (Active Learning Processes: Natural World) (see Figure 1).
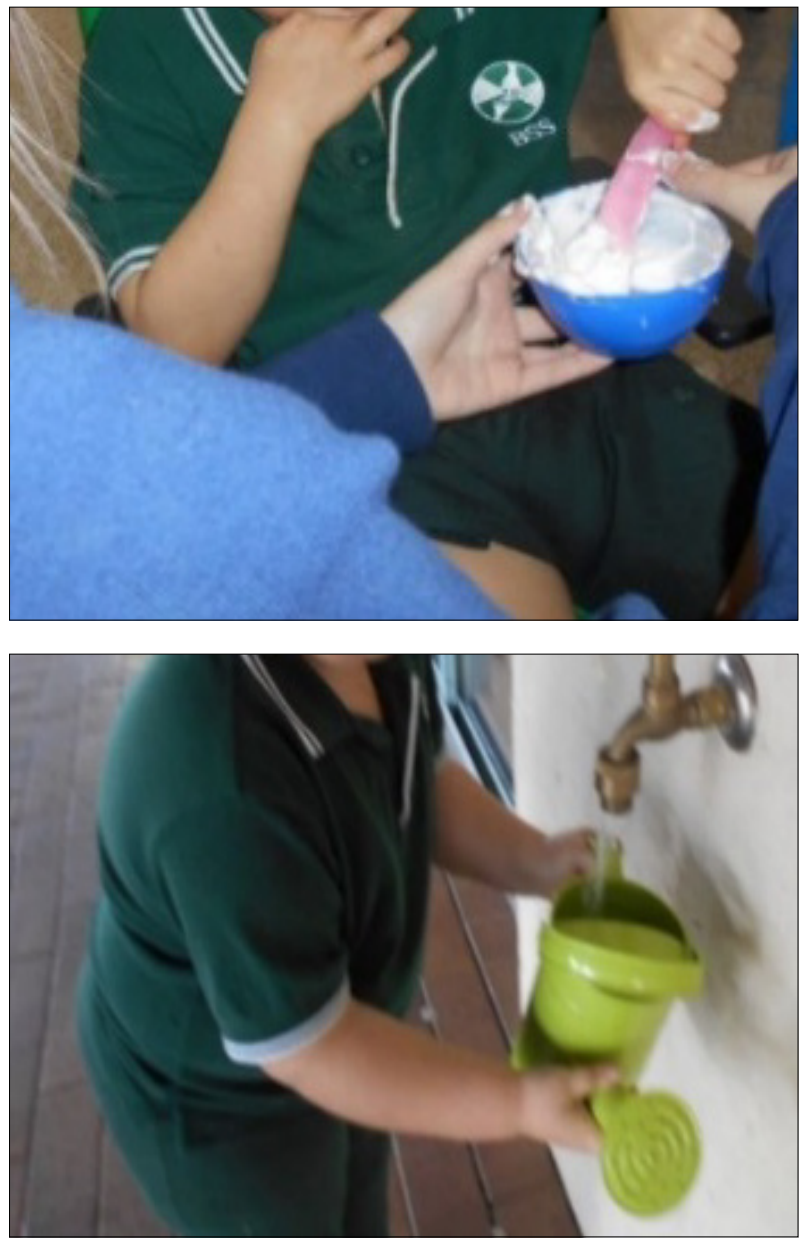

Figure 1. Asha, Joe and Rose exploring full and empty

Other integrated learning activities included: 1) students sitting in a line to throw beanbags. Tape was stuck to the floor from each of the students' chairs to assist with identifying which beanbag had been thrown the furthest. This activity prompted discussions and use of language associated with near, far, length and so on, 2) students throwing beanbags at a target. The target was initially put near the students and gradually moved further away. I supported and encouraged the students to use basic language to discuss how and why it became more difficult to hit the target, 3) Students were encouraged to use blocks to build towers. They made direct comparisons of toys/attributes in relation to specified attributes. I modelled how to use string to measure arms, feet and length. Each student chose a different coloured string. The different lengths were added to a chart that make it easy to compare and answer questions to help students to order length (see Figure 2).

The assessment used for this series of activities required that the students had to understand the measurement topic and its natural continuous state (without using numbers). In doing so, it prompted the question: Where is the student now?

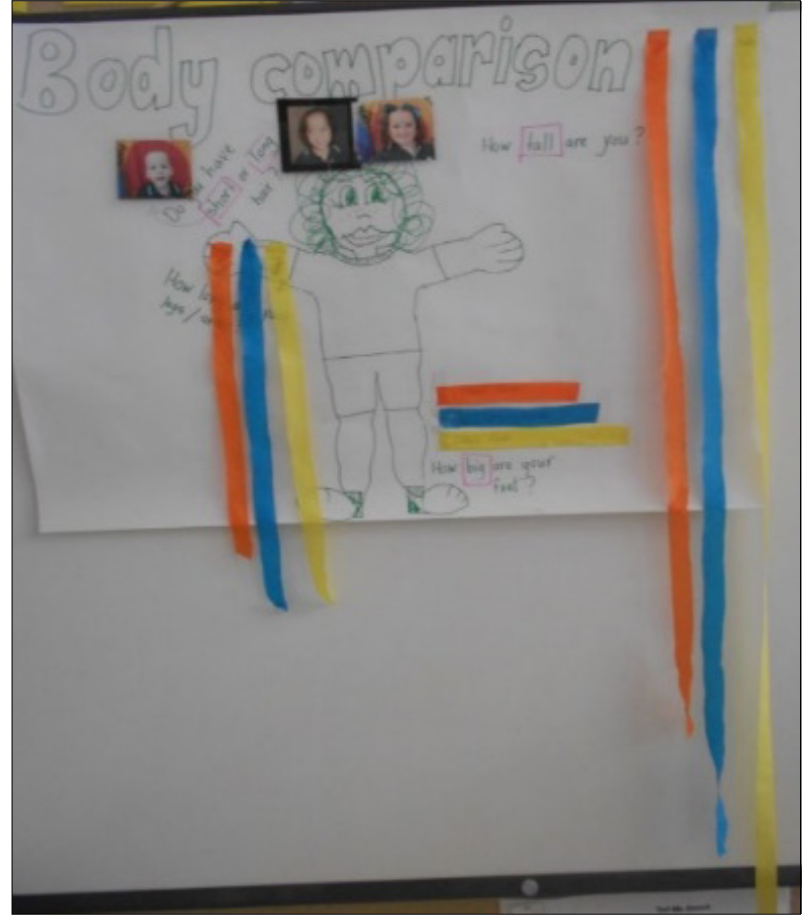

Figure 2. Ordering length

Joe and Asha did not demonstrate an increased understanding of the measurement attributes. Celia was beginning to engage with me to build towers and she looked at items that were presented and needed to be compared but she needed more opportunities to consolidate her understanding of what was required. Rosco demonstrated an increased understanding of the attributes that related to specified measures and she 'compared' things as modelled by me but she did not consistently indicate 'same and different'. Fraser and Rose demonstrated sufficient understanding of similarities and differences and an ability to order three objects was developing.

\subsection{Where Will I Take the Students next?}

Asha and Joe continued to manipulate objects in an effort to enhance their awareness of the attributes of measures. Celia continued to engage with staff to increase her ability to perceive similarities and differences. Rosco's ability to indicate similarities and differences was developed through more opportunities to compare and consider attributes. Fraser and Rose were encouraged to use non-standard units to measure things. They were exposed to more opportunities to order three items to develop flexible thinking, visual thinking and logical thinking. At this stage of the students' progress I considered taking some of the students into stage 3 of the measurement framework-non-standard units of measure.

Stage 3 of the learning sequence was the first time that numbers were introduced to the measurement activities. Stage 3: Non-standard units has two central uses: 1) introduce the notion of the unit and, 2) measuring technique. 
This stage introduces the measurement process and as well introducing students to appropriate techniques for using units and for using measuring instruments. Any objects that could be used as units e.g. hand spans, pencils, counters, blocks were used. By using non-standard units, students could be helped to realise the need and benefits in having standard units. Examples of activities included: 1) presenting students with popsicle sticks, strings, paper strips, craft hands and feet and blocks. I prompted the students' thinking by asking questions such as 'How long?' Brainstorming and discussion with the students worked to support students with telling how long/tall an object and whether it was longer/shorter/taller. Students investigated using different equipment as I actively observed, 2) Students filled bottles of different sizes with water using a $250 \mathrm{ml}$ measuring jug. I engaged them in discussions about how many jugs full of water had gone into each bottle. This activity brought in counting, in particular one-to-one correspondence.

Fraser enjoyed building towers with blocks. He was beginning to look for a reference when he built his towers, for example, he always tried to make the Lego tower taller than himself and he used the small wooden blocks to build a tower as high as the dinosaur. Rosco and Celia continued to use blocks to build towers or to put in a line from one end of the table to the other. Fraser and Rose faced a problem - they needed to find out the length of the snake against the blue lines provided. I helped them to use a piece of string as an intermediary to measure the snake. They then compared the string to each blue line until they got a match - it was (almost) as long as the longest blue line!

\subsection{Where are the Students now?}

An assessment of where the students were at as a consequence of the sequence of activities was done in week 9 . Celia was not interested in using the blocks at the beginning of the unit. She would throw the blocks and sweep the ALS board off the table. However, after a few weeks she started to stack the blocks until they fell over. She did this activity over and over. The teacher aide and I engaged with her to model appropriate language and to give praise. She enjoyed experimenting with the liquids but her interest related more to the play aspect. Rosco was beginning to count the blocks as she stacked them by pointing to each block. She played with the items that are used for capacity and mass but she did not yet demonstrate an awareness of the measures as such. Fraser and Rose made random comments about objects they encountered by vocalising an attribute, for example, heavy, light. They needed more experiences with capacity and mass to consolidate their understanding of these attributes.

\subsection{Abstraction and Working Towards Mathematics: Where Will the Teacher Take the Students Next?}

In week $10 \mathrm{I}$ observed the activities that elicited the greatest engagement from each student. I then engaged with them to demonstrate language and how to use equipment efficiently. The activities included: Cooking: Fraser and
Rose were encouraged to add ingredients to a jug by following a basic recipe with the help of an adult to make a banana smoothie. They used standard sets of measuring cups and spoons.

I introduced basic terminology such as a litre (standard unit of measure), a cupful and a spoonful (non-standard units of measure). Fraser's ability to count and identify numerals up to 30 was developing well. He worked with me to use a 30 $\mathrm{cm}$ ruler to measure objects in the classroom for specific purposes, for example measuring the length of a desk and the width of the door opening to determine if the desk would go through the opening. The term centimetres was introduced. He was aware that a ruler or measuring tape was used to determine the length of objects. He attempted to 'measure' something whenever he got hold of one of a variety of rulers that were readily available in the classroom. Rosco was encouraged to use and count non-standard units other than blocks to measure objects. Celia continued to use blocks to make long tracks and high towers that were as long as something in the room. The teacher modelled counting and worked with her to understand that the bigger the block, the smaller the amount and the smaller the block the larger the amount. All the students engaged enthusiastically in the activities but did require a lot of support to complete tasks and to understand that it is not merely play.

The challenge was to help students understand why we do things a certain way and why we used specific equipment for certain tasks. The students were encouraged to measure a range of objects in their environment. I prompted the students regularly by asking questions and to help them to apply their knowledge to other situations. The students in this group may be working at the Abstraction/Mathematics phase for a few years. It is important to track their progress in order to provide them with the best opportunities possible.

\section{Discussion}

The Disability Discrimination Act and the Education Standards in mainstream schooling was examined. A discussion of implications for educational practice and reasonable adjustments for learning follows. With respect to educational practice and reasonable adjustments in special education, several findings are of particular interest. First, in special education settings making reasonable adjustments to a students' learning program is a complex, constant and continual process throughout the action of teaching. It requires ongoing observation and continual micro- adjusting of teaching based on the teacher's observations of the students and how they interact and engage in the learning process. Micro-adjusting is informed by students' performance on tasks (Ewing, 2016a) [42].

When a student is not succeeding, the teacher adjusts the task to one closely related to the original task. A student's learning program must be adjusted from lesson to lesson and from moment to moment within lessons. That support keeps a child at the cutting edge of his or her competencies, in his 
or her continually changing zone of proximal development. (p. 7)

Second, determining the amount of micro-adjustment requires a high degree of understanding of pedagogical content knowledge in mathematics and regulation on the part of the teacher and their ability to scaffold the students' learning. Scaffolds are adjustable and temporarily used to help extend the range of work that students engage in and accomplish tasks not otherwise possible. In Jelene's reflection, such scaffolds were evident particularly when she was discussing Fraser and his distraction with printed material, indicating that "much prompting" was required for Fraser to stay on task. Scaffolding and prompting are closely connected. Prompting takes much practice and experience (Lyons et al., 1993, p. 157) [43]. The task for teachers is to develop the skills to observe closely what individual students are doing, decide what kind of information the student needs to attend to, and then select the prompt that will assist the student. Effective scaffolders focus and prompt student's attention on tasks and keep them motivated and working throughout the lesson.

Scaffolding refers to the gradual release of teacher control and support as a consequence of students' increasing mastery (Bruner, 1996) [44]. The teacher divides the task into accessible components and directs the student's attention to the essential and relevant features as was evident in Jelene's reflection as she worked with the students through stages 1 and 2 of measurement. As she modelled and represented measurement attributes such as length, mass and capacity she scaffolded the students' learning and appears to keep the task at a proper level of difficulty, avoiding unnecessary frustration and encouraging students' independent learning. Jelene's reflection of her teaching seems consistent with Bruner's (1985)[45] description of scaffolding:

If the child, is enabled to advance by being under the tutelage of an adult or a more competent peer, then the tutor or the aiding peer serves the learner as a vicarious form of consciousness until such a time as the learner is able to master his [her] own action through his [her] own consciousness and control. When a child achieves that conscious control over a new function, it is then that he [she] is able to use it as a tool. (p. 24)

Jelene's reflection demonstrated a high degree of skill and regulation - adjusting the amount of scaffold to take account the students' new learnings and anticipating and supporting the students' next steps. As part of the professional learning program focus, teachers were to consider their pedagogical approach and pedagogical content knowledge and reflect on how both could be strengthened, modified or changed. Asking teachers to change and or modify their practice is a process and takes time.

Third, throughout Jelene's reflection the process of modifying or changing her practice required a high level of commitment and efficacy. Change for teachers is often seen as difficult, uncomfortable and stressful, even when it is for the better (Fullan, 2006) [46]. Change can have a negative effect on teachers' personal teaching efficacy. Change challenges teachers' existing beliefs about the effectiveness of their pedagogical practice. There were indications that Jelene was confident but also challenged with her practice, however, she demonstrated her responsiveness to the differential needs of all the students - making reasonable and in some cases substantial adjustments and removing the barriers for the students so they could engage, learn, participate and achieve. To address any slumps in confidence, teachers need encouragement, support and feedback as they learn about new approaches and then trial and implement them into their classrooms.

Fourth, in order to make reasonable adjustments whether they are supplementary, substantial or extensive teachers need to have a solid understanding of their pedagogical content knowledge in mathematics. There continues to be a strong consensus in teacher education literature that going beyond the dispensing of content, i.e., giving a test or grade, is the challenge for this century. Its resolution will depend on schools' and teachers' abilities to develop knowledge that supports and enhances more strategic learning and understanding of how to teach and organise schools in ways that respond to students' diverse approaches to learning (Darling-Hammond, 2016, p. 85) [47]. Whilst teacher content knowledge is crucially important for improving teaching and learning, historically there has been a tendency to focus on such content, with scant attention paid to how teachers must understand the content of the subjects that they teach (Loewenberg Ball et al., 2008)[48]. More recent findings show that content knowledge continues to be inert in classrooms unless it is accompanied by a rich repertoire of knowledge and skills related directly to the curriculum, instruction and student learning (Baumert, 2010, Darling-Hammond, 2016)[49, 48]. Shulman (2005, 1986) $[50,51]$ refers to pedagogical content knowledge as highly quality instruction that requires sophisticated pedagogical content knowledge. The appeal of this knowledge is that it bridges the content knowledge and the practice of teaching. It affords conversations of content relevant to teaching and conversations of teaching related to content. It is a most useful way of representing and formulating content knowledge so that it is comprehensible to others. It underlies the design and selection of tasks, choice of representations and explanations and the facilitation of productive classroom discourse. A profound understanding of content or subject matter is necessary but far from sufficient for rich and insightful instruction (Hashweh, 2014) [52].

\section{Implications for Practice}

Regardless of one's opinion of reasonable adjustment the results from this study provide sufficient evidence that demonstrates that making adjustments is highly individualised, comprehensive and ongoing. It requires strong knowledge and skill with differentiated teaching 
practice to ensure that students access the curriculum at appropriate year levels. The DDA and Education Standards (Commonwealth of Australia, 2005)[1] mandates that students with disability should be accessing and participating in education on the same basis as other students and that reasonable adjustments are made to their learning program. Scaffolding, prompting, modifying and or changing practice and refining pedagogical content knowledge requires risk taking, confidence and the capacity to reflect on practice. To do this, requires extensive knowledge and skill from the teacher who should have a profound interest in their students' learning. When teachers take an interest in, and notice, students' thinking during maths lessons, deep and sustained transformations occur in teachers' and students' efficacy. They are provided with efficacy information that sustains the motivation to keep teaching the kinds of lessons that are successful, increasing their efficacy as well as that of their students.

To conclude, it is difficult to consider all the complexities related to the teaching and learning of mathematics in special schools. Teachers will continue to teach mathematics based on their content knowledge and pedagogical content knowledge. However, the quality of the teaching will be under the control of the teacher. Although more research needs to be done to arrive at a more definitive conclusion, it appears that such things as reasonable adjustment has an effect on students' learning and progression and, thereby, indirectly, on their identities as learners in the social context of the classroom. It also has an effect on teachers' professional efficacy. Policy makers should be aware of this. Policy that encourages reasonable adjustments and at the same time promotes quality differentiated teaching practice seems to be working parallel to one another because of the lack of high level support needed to assist teachers in such complex teaching contexts.

\section{REFERENCES}

[1] COMMONWEALTH OF AUSTRALIA 2005. Disability Standards for Education 2005. Canberra.

[2] DICKSON, E. 2013. Disability standards for education and reasonable adjustment in the tertiary education sector. Available:

http://www.anzela.edu.au/assets/anzjle_vol_12.2_-_2_dickso n.pdf [Accessed 16/07/2016].

[3] LIACHOWITZ, C. H. 1988. Disability as a social construct: Legislative roots, Pennysylvania, University of Pennysylvania Press.

[4] EDUCATION SERVICES AUSTRALIA. 2014. Nationally consistent collection of data: school students with disability [Online]. Available:

http://www.schooldisabilitydatapl.edu.au/data-collection-step s/step-1---is-there-an-adjustment [Accessed 16/01/2016.

[5] ORGANISATION FOR ECONOMIC COOPERATION AND DEVELOPMENT 2011. Sickness, disability and work Improving social and labour - market integration of people with disability.

[6] UNESCO. 2009. Towards Inclusive Education for Children with Disabilities: A Guideline [Online]. Available: http://www.uis.unesco.org/Library/Documents/disabchild09en.pdf [Accessed 13/12/2014.

[7] EUROPEAN AGENCY FOR DEVELOPMENT IN SPECIAL NEEDS EDUCATION. 2012. The inclusive education in action project [Online]. Available: https://www.european-agency.org/agency-projects/iea [Accessed 12/04/2016.

[8] UNICEF. 2014. Children with disabilities [Online]. Available: http://www.unicef.org.au/Discover/Issues-facing-children/Pro tection/Children-with-Disabilities.aspx[Accessed 19/08/2014.

[9] JAHNUKAINEN, M. 2011. Different strategies, different outcomes? The history and trends of the inclusive and special education in Alberta (Canada) and in Finland. Scandinavian Journal of educational Research, 55, 489-502.

[10] FERRI, B. A. 2015. Integrazione scholastica: on not having all of the answers - a response to Anastasiou, Kauffman and Di Nuovo. European Journal of Special Needs Education, 30, 444-447.

[11] ALBERTA EDUCATION. 2016. Available: https://education.alberta.ca/inclusion/what-is-inclusion/ [Accessed 15/04/2016.

[12] US DEPARTMENT OF EDUCATION. 2008. Education and inclusion in the United States [Online]. Available: http://www.ibe.unesco.org/National_Reports/ICE_2008/usa NR08.pdf [Accessed 13/05/2016.

[13] UNICEF. 2007. Promoting the rights of children with disabilities [Online]. Available: http://www.un.org/esa/socdev/unyin/documents/children_disa bility_rights.pdf [Accessed 23/05/2016.

[14] UNESCO. 1994. Salamanca Statement and Framework to Action [Online]. Available: http://www.unesco.org/education/pdf/SALAMA_E.PDF [Accessed 25/06/2015.

[15] BAKKER, J., DENESSEN, E., BOSMAN, A., KRIJGER, E., BOUTS, L., 2007. Sociometric students and self-image of children with specific and general learning disabilities in Dutch general and special education classes. Learnin Disability Quarterly, 30, 47-62.

[16] ALLPORT, G. W. 1954. The nature of prejudice, Oxford, Uk, Addison-Wesley.

[17] MARAS, P. B., R. 2000. Effects of different forms of school contact on children's attitudes toward disabiled and nondisabled peers. British Journal of Educational Psychology, 70, 337-351.

[18] BRYAN, T. 1974. Peer popularity of learning disabled children. Journal of Learning Disabilities, 7, 31-35.

[19] KUHNE, M., \& WIENER, J., 2000. Stability of social status with and without learning disabilities. Learning Disability Quarterly, 23, 64-75.

[20] STONE, W. L., \& LA GRECA, A. M., 1990. The social status of children with learning disabilities. A re-examination. Journal of Learning Disabilities, 23, 364-371.

[21] BAKKER, J., \& BOSMAN, A., 2003. Self-image and peer acceptance od Dtch students in regular and special education. Learning Disability Quarterly, 26, 5-14. 
[22] WIENER, J., HARRIS, P., SHIRER, C., 1990. Achievement and social-behavourial correlates of peer status in learning disabilities children. Learning Disability Quarterly, 13, 114-127.

[23] DEPARTMENT OF EDUCATION AND TRAINING. 2016. Enrolment in State Primary, Secondary and Special Schools [Online]. Available:

http://ppr.det.qld.gov.au/education/management/Pages/Enrol ment-in-State-Primary,-Secondary-and-Special-Schools.aspx

[24] EWING, B. F. 2016b. Making Sense of a Trial Maths Intervention Program for Students with Disability in Australia: Interim Report. Universal Journal of Educational Research, 4, 2299-2311.

[25] DEPARTMENT OF EMPLOYMENT. 2015. Labour market research - school teachers [Online]. Department of Employment, Australian Government. Available: https://docs.employment.gov.au/system/files/doc/other/school teachersaus.pdf [Accessed 12/03/2016.

[26] CLOUGH, P. 2006. Bridging 'mainstream' and 'special' education: a curriculum problem. Journal of Curriculum Studies, 20, 327-338.

[27] MULCAHY, C. A., KREZMIEN, M. P. \& TRAVERS, J. 2016. Improving Mathematics Performance Among Secondary Students With EBD: A Methodological Review. Remedial and Special Education, 37, 113-128.

[28] BROWDER, D. M., SPOONER, F., AHLGRIM-DELZELL, L., HARRIS, A. A. \& WAKEMAN, S. 2008. A Meta-Analysis on Teaching Mathematics to Students With Significant Cognitive Disabilities. Exceptional children, 74, 407-432.

[29] AUSTRALIAN CURRICULUM REPORTING AND ASSESSMENT AUTHORITY. 2011a. Foundation to Year 10 Mathematics [Online]. Available:

$\mathrm{http} / / /$ www.australiancurriculum.edu.au/mathematics/curricul um/f-10?layout=1 [Accessed 23/11/2012.

[30] FORD, N., \& ASHFORD, G.,. 2000. Appreciative inquiry [Online]. Ottawa, Ontario: Participatory Development Forum. Available: http://www.pdforum.org/eviews1.html

[31] HAMMOND, S. 1996. The Thin Book of Appreciative Inquiry [Online]. Available: http://www.thinbook.com/appreciative-inquiry/.

[32] MATTHEWS, C. 2008. Stories and symbols: Maths as storytelling [Online]. Available: http://www.aeu-vic.labor.net.au/professional/files/PV Mathe ws_6_3.pdf [Accessed 24/08/09.

[33] PAYNE, J., \& RATHMELL, E., 1975. Number and Numeration'. In: PAYNE, J. N. (ed.) Mathematics learning in early childhood. Reston VA: National Council for Teachers of Mathematics.

[34] BRUNER, J. 1960. The process of education, Cambridge, Mass, Harvard University Press.

[35] AUSTRALIAN BUREAU OF STATISTICS. 2006. Socio-economic status [Online]. Available: http://www.abs.gov.au/ausstats/abs@.nsf/Lookup/4250.0.55. 001Main+Features32009 2024].

[36] AUSTRALIAN CURRICULUM REPORTING AND
ASSESSMENT AUTHORITY. 2011b. General capabilities [Online]. Available:

http://www.acara.edu.au/verve/_resources/General_Capabiliti es_2011.pdf [Accessed 24/12/2013.

[37] QCAA. 2006. Early Years Curriculum Guidelines [Online]. Available: https://www.qcaa.qld.edu.au/downloads/p_10/ey_cg_06.pdf.

[38] WECHSLER, D. 2012. Wechsler preschool and primary scale of intelligence. Third Edition, San Antonio, TX, The Psychological Corporation.

[39] WILSON, P., \& ROWLAND, R., 1993. Chapter 8. In: JENSEN, R. J. (ed.) Research ideas for the classroom. NJ: NCTM Macmillan.

[40] SPECTRONICS. 2015. BIGmack communicator [Online]. Available:

http://www.spectronics.com.au/product/bigmack-communicat or-enhanced [Accessed 12/12/2016 2016].

[41] SEVCIK, R. A., \& ROMSKI, M.,. 2016. AAC: More Than Three Decades of Growth and Development, [Online]. American Speech-Language-Hearing Association. Available: http://www.asha.org/public/speech/disorders/AACThreeDeca des/ [Accessed 12/12/2016 2016].

[42] EWING, B. 2016a. The identification of teaching interactions used in one-to-one teaching of number in the early years of schooling. Cogent Education, 3, 1132525.

[43] LYONS, C. A., PINNELL, G. S. \& DEFORD, D. E. 1993. Partners in learning: teachers and children in reading recovery, New York, Teachers College Press.

[44] BRUNER, J. 1996. The culture of education, Cambridge, Harvard University Press.

[45] BRUNER, J. 1985. Vygotsky: A Historical and Conceptual Perspective. In: WERTSCH, J. V. (ed.) Culture, Communication and Cognition: Vygotskian Perspectives. Cambridge: Cambridge University Press.

[46] FULLAN, M. 2006. Change theory. A force for school improvement. Seminar series paper No. 157, November. Centre for Strategic Education

[47] DARLING-HAMMOND, L. 2016. Research on teaching and teacher education and its influences on policy and practice. Educational Researcher, 45, 83-91.

[48] LOEWENBERG BALL, D., THAMES, M. H. \& PHELPS, G. 2008. Content Knowledge for Teaching: What Makes It Special? Journal of Teacher Education, 59, 389-407.

[49] BAUMERT, J. E. A. 2010. Teachers' Mathematical Knowledge, Cognitive Activation in the Classroom, and Student Progress. American Educational Research Journal, 47, 133-180.

[50] SHULMAN, L. S. 1986. Those Who Understand: Knowledge Growth in Teaching. Educational Researcher, 15, 4-14.

[51] SHULMAN, L. S. 2005. Signature pedagogies in the professions. Daedalus, 134, 52-59.

[52] HASHWEH, M. 2014. Encyclopedia of Educational Theory and Philosophy. Thousand Oaks, California: SAGE Publications, Inc. 